\title{
Natural history observations in moderate aortic stenosis
}

\author{
Yu Du ${ }^{1,2}$, Mario Gössl', Santiago Garcia ${ }^{1}$, Maurice Enriquez-Sarano ${ }^{1}$, Joao L. Cavalcante ${ }^{1}$, Richard Bae , \\ Go Hashimoto ${ }^{1}$, Miho Fukui ${ }^{1}$, Bernardo Lopes ${ }^{1}$, Aisha Ahmed ${ }^{1}$, Christian Schmidt ${ }^{1}$, Larissa Stanberry', \\ Ross Garberich', Steven M. Bradley ${ }^{1}$, Robert Steffen ${ }^{1}$ and Paul Sorajja ${ }^{1 *}$ (D)
}

\begin{abstract}
Background: The natural history of patients with moderate aortic stenosis (AS) is poorly understood. We aimed to determine the long-term outcomes of patients with moderate AS.

Methods: We examined patients with moderate AS defined by echocardiography in our healthcare system, and performed survival analyses for occurrence of death, heart failure (HF) hospitalization, and progression of AS, with accounting for symptoms, left ventricular dysfunction, and comorbidities.

Results: We examined 729 patients with moderate AS (median age, 76 years; $59.9 \%$ men) with a median follow-up of 5.0 years (interquartile range: 2.0 to 8.1 years). The 5-year overall survival was 52.3\% (95\% confidence interval [CI]: $48.6 \%$ to $56.0 \%$ ) and survival free of death or HF hospitalization was $43.2 \%$ (95\% Cl: $39.5 \%$ to $46.9 \%$ ). Worse New York Heart Association (NYHA) functional class was associated with poor long-term survival, with mortality rates ranging from $7.9 \%$ (95\% Cl: 6.6-9.2\%) to $25.2 \%$ (95\% Cl: 20.2-30.3\%) per year. Among patients with minimal or no symptoms, no futility markers, and preserved left ventricular function, 5-year overall survival was $71.9 \%$ (95\% Cl: 66.4-77.4\%) and survival free of death or HF hospitalization was $61.4 \%$ (95\% Cl: 55.5-67.3\%). Risk factors associated with adverse events were age, NYHA class, low ejection fraction and high aortic valve velocity (all $p<0.05$ ).
\end{abstract}

Conclusions: Patients with moderate AS are at significant risk of death. Our findings highlight the need for more study into appropriate therapeutic interventions to improve the prognosis of these patients.

Keywords: Moderate, Aortic stenosis, Outcomes, Survival, Aortic valve replacement

\section{Background}

Aortic stenosis (AS) is one of the most common valvular diseases, with a growing number of patients due to population aging. Among those over 65 years of age, the prevalence of moderate or severe AS is 2 to $4 \%$, with 1.5 to 3 million afflicted patients in the U.S. alone [1]. Thresholds for intervention have been traditionally defined by assessment of symptoms and echocardiographic

\footnotetext{
*Correspondence: paul.sorajja@allina.com

${ }^{1}$ Roger L. and Lynn C. Headrick Chair, Valve Science Center, Minneapolis Heart Institute Foundation, Abbott Northwestern Hospital, Minneapolis, MN 55407, USA

Full list of author information is available at the end of the article
}

parameters of stenosis severity $[2,3]$. To date, the major focus in the management of AS has been on the identification of those with symptomatic severe stenosis, in whom aortic valve replacement (AVR) is well established as a life-saving therapy $[2,3]$. Nevertheless, AS, even when defined as moderate in severity, may impart hemodynamic effects that could burden patients and potentially be associated with heart failure (HF) and impairment in long-term survival [4-9]. Such observations have implications for treatment thresholds for patients with AS, but remain limited due to confounding factors such as symptoms, morbidities, and concomitant left ventricular (LV) dysfunction [4-9]. Accordingly, we 
undertook this real-world, longitudinal study of a large cohort of patients with moderate AS in order to better define the natural history of moderate AS.

\section{Methods \\ Study population}

The Allina Health System is a private, nonprofit healthcare system that provides care for patients from Minnesota and western Wisconsin, comprised of 3 tertiary and 9 rural hospitals, and more than 90 outpatient clinics. All patients seen between January 2010 and March 2012 in the Allina Health System were considered for enrollment in the present investigation. We examined the initial two-dimensional and Doppler echocardiogram (index echocardiogram) of each patient seen during this time period, and enrolled those with a diagnosis of moderate AS, as defined by the presence of one of the following criteria: (1) peak aortic velocity of 3.0 to $4.0 \mathrm{~m} / \mathrm{s}$; (2) mean aortic gradient of 20 to $40 \mathrm{mmHg}$; (3) aortic valve area (AVA) of 1.0 to $1.5 \mathrm{~cm}^{2}$; (4) indexed AVA of 0.60 to $0.85 \mathrm{~cm}^{2} / \mathrm{m}^{2}$; or (5) a dimensionless index (DI) of 0.25 to 0.50 [10]. Exclusion criteria for the study were: (1) age $<18$ years; (2) prior AVR or aortic valve repair; (3) severe mitral, tricuspid, or pulmonary valve disease; (4) severe aortic regurgitation or evidence of supra- or subaortic stenosis; and (5) hemodynamic findings consistent with severe AS (i.e., peak aortic velocity $\geq 4 \mathrm{~m} / \mathrm{s}$, mean aortic gradient $\geq 40 \mathrm{mmHg}$, or AVA $<1.0 \mathrm{~cm}^{2}$ ). The study was approved by the Allina Institutional Review Board and was performed in accordance with the Declaration of Helsinki.

\section{Data collection and definitions}

Each electronic medical record was reviewed for patient demographics, cardiac symptoms, and morbidities present at the time of the index echocardiogram, and subsequent clinical outcomes. The index echocardiogram was the first echocardiogram during the study period that identified moderate AS patients without exclusion criteria for enrollment. AVA was calculated using the continuity equation. DI was calculated as the ratio of the LV outflow tract velocity time integral (VTI) and to the aortic valve VTI [11]. LV mass index was calculated using the Devereux formula [12]. Patients were classified into New York Heart Association (NYHA) functional class on the basis of the presence of dyspnea. Potential futility markers were defined as: (1) oxygen-dependent severe lung disease; (2) liver disease with model for end-stage liver disease score $\geq 12$; (3) end-stage renal disease on dialysis; (4) excessive frailty; (5) severe dementia; or (6) malignancy with life expectancy $<1$ year [13-15].

Clinical outcomes in follow-up evaluations were obtained by review of medical records or telephone interview. The primary clinical outcome of interest in the study was all-cause mortality. Other clinical outcomes were occurrence of HF hospitalization, the combined endpoint of death or HF hospitalization, myocardial infarction (MI), stroke, progression of AS to the severe range, and occurrence of transcatheter or surgical AVR. Standard definitions of HF hospitalization, MI, and stroke were utilized $[16,17]$.

\section{Data analysis}

Three patient groups were defined according to baseline NYHA functional class (I, II, or III/IV). Continuous data were summarized by medians and interquartile ranges (IQR), and compared using a Kruskal-Wallis $\mathrm{H}$ test. Categorical variables were summarized by counts (\%) and compared using either a Chi-squared test or a Fisher's exact test as appropriate. For each endpoint, incidence rates per 100 person-years of follow-up and their $95 \%$ confidence intervals (CI) were calculated using a Poisson distribution. Kaplan-Meier survival curves were estimated for each primary endpoint and compared between different NYHA functional classes using a log-rank test, with and without censoring for occurrence of AVR, and with and without exclusion of patients with potential futility markers or LV ejection fraction $<50 \%$. Further, a one-sample log-rank test was also used to compare the survival free of death for the select patient subgroups with that of the total age- and gender-matched Minnesota population based on the 2013 life tables. Individual expected survival estimates were computed and used to estimate the incident risks of all-cause mortality with a Poisson model adjusted for a sex-specific baseline mortality due to age.

Multivariate Cox proportional hazard models were used to estimate the association between the risk of adverse events and underlying clinical and demographic factors with AVR modeled as a time-dependent variable. All models were stratified by gender, adjusted for age and body surface area, and included NYHA functional class; the body surface area was included to account for the effect of body size on cardiovascular parameters. Other candidate explanatory variables collected at index echocardiogram including continuous measurements of blood pressure, blood pressure medication prescription, mean aortic gradient, peak aortic velocity, LV ejection fraction, body mass index, stroke volume index; binary indicators of moderate or severe mitral regurgitation, moderate or severe tricuspid regurgitation, moderate or severe right ventricular systolic dysfunction, hypertension, diabetes, current smoking status, coronary artery disease, prior MI, prior percutaneous coronary intervention, prior coronary artery bypass grafting, prior stroke or transient ischemic attack, chronic lung disease, 
peripheral artery disease, dialysis, anemia, malignancy, permanent pacemaker, implanted defibrillator. Also included were futility markers of oxygen-dependent severe lung disease, end-stage renal disease, and excessive frailty; since only two patients in the study had endstage liver disease and only four had severe dementia, these markers were not included separately but aggregated into broader binary indicators of dementia and liver disease; malignancy was included as a three-level factor: none, malignancy with expected survival of more and of less than one year. A final model was constructed using a stepwise forward selection and backward elimination algorithm with a generalized Akaike information criterion. The estimated associations are reported together with their $95 \% \mathrm{CI}$ and $\mathrm{p}$-values. The variable selection and analyses were repeated for patients without futility markers. Data analysis was conducted using SPSS 22 (IBM, Armonk, New York) and R v4.0 in RStudio v1.3 environment (RStudio PBC).

\section{Results}

\section{Patient characteristics}

Overall, 729 patients with moderate AS (median age, 76 years [IQR: 67 to 84 years]; $59.9 \%$ men) were enrolled in the study (Table 1, Additional file 1: Figure 1). The vast majority $(93.1 \%)$ were white, and with a history of hypertension $(80.2 \%)$ or dyslipidemia (71.3\%). Coronary artery disease was present in 365 patients (50.1\%) with 197 patients (27.0\%) having prior MI. Overall, 423 patients $(58.0 \%)$ had symptoms of dyspnea that were more than mild (i.e., NYHA functional class II or worse). The prevalence of morbidities increased with worse NYHA class, and potential futility markers were present in 90 patients (or $12.3 \%$ ) in the overall study population.

Overall, the median AVA was $1.51 \mathrm{~cm}^{2}$ (IQR: 1.34 to $1.73 \mathrm{~cm}^{2}$ ) with a median aortic valve gradient of 9.1 $\mathrm{mmHg}$ (IQR: 5.9 to $14.0 \mathrm{mmHg}$ ) (Table 2). The LV ejection fraction was preserved in the majority of patients (71.6\%) with a median value of $58 \%$ (IQR: $45 \%$ to $63 \%$ ). Worse NYHA class was associated with lower aortic valve velocity, mean aortic gradient, LV ejection fraction, and stroke volume index (all $p<0.001$ ). Higher AVA, larger LV end-diastolic diameter, and more mitral and tricuspid regurgitation also were more common in those with worse NYHA functional class (all $p<0.01$ ).

\section{Clinical outcomes}

Clinical follow-up was complete in all patients with a median time of 5.0 years (IQR: 2.0 to 8.1 years), and any death occurred in 453 patients (or 62.1\%) with an estimated survival time of 5.5 years ( $95 \%$ CI: 4.8 to 6.2 years). Overall, 5-year survival was $52.3 \%$ (95\% CI: $48.6 \%$ to
$56.0 \%$ ), with an incidence of 12.6 (95\% CI: 11.4 to 13.7) per 100 person-year (Fig. 1; Table 3). In the entire study group, HF hospitalization occurred in 211 patients (or $28.9 \%$ ), with an incidence of 6.7 (95\% CI: 5.8 to 7.6) per 100 person-year (Table 3). For the combined endpoint of death or HF hospitalization, the 5-year survivorship was $43.2 \%$ (95\% CI: $39.5 \%$ to $46.9 \%$ ), with an incidence of 16.3 (95\% CI: 14.9 to 17.7 ) per 100 person-year (Table 3).

Worse NYHA class was related to higher rates of any death, HF hospitalization and the combined endpoint of death or HF hospitalization (all $p<0.05$ ) (Table 3). Notably, among 306 patients with minimal or no symptoms (i.e., NYHA class I), the 5-year survival was $66.1 \%$ (95\% CI: $60.8 \%$ to $71.4 \%$ ), with an incidence of 7.9 (95\% CI: 6.6 to 9.2) per 100 person-year (Fig. 2; Table 3). For the combined endpoint of death or HF hospitalization, the 5-year survival for the NYHA class I patients was $57.1 \%(95 \%$ CI: 51.4-62.8\%), with an incidence of 10.7 (95\% CI: 9.2 to 12.3 ) per 100 person-year (Fig. 2; Table 3).

The trends in the rates of death and the combined endpoint of death or HF hospitalization were similar when patients with potential futility markers were excluded (all $p<0.001$ ) (Table 3). Among the 639 patients without potential futility markers, the survival was $57.4 \%(95 \%$ CI: $53.5-61.3 \%)$ at 5 years, and was $47.8 \%$ (95\% CI: $43.9-$ $51.7 \%)$ at 5 years for the combined endpoint of death or HF hospitalization. Of note, for patients who had minimal or no symptoms (NYHA I) and who also were without potential futility markers $(n=283)$, the 5 -year overall survival and survival free of the combined endpoint of death or HF hospitalization were $70.5 \%$ (95\% CI: $65.2-$ $75.8 \%$ ) and $60.7 \%$ (95\% CI: 55.0-66.4\%), respectively. In addition, the 5 -year overall survival was $58.2 \%(95 \%$ CI: $53.9-62.5 \%)$ among 522 patients with preserved LV systolic function $(\geq 50 \%)$, while in whom with NYHA I, the survival was $67.6 \%$ (95\% CI: $62.1-73.1 \%$ ) at 5 years. Moreover, this survivorship was similar when analyses were restricted to patients with minimal or no symptoms, without potential futility markers, and with preserved LV ejection fraction. In these patients $(\mathrm{n}=262)$, the 5-year survival was $71.9 \%$ (95\% CI: 66.4-77.4\%) with a death rate of 6.8 (95\% CI: 5.5 to 8.0) per 100 person-year.

\section{Progression to AVR and censoring}

Echocardiographic follow-up was available in 517 patients (71\% of the cohort), at a median interval of 4.3 years (IQR: 2.3 to 6.8 years). Among them, 89 of these patients $(17.2 \%)$ had progression to severe AS, with an incidence of 3.9 ( $95 \%$ CI: 3.1 to 4.7 ) per 100 person-year (Fig. 3; Table 3). Overall, AVR occurred in 83 patients (transcatheter, 55.4\%; surgical, 44.6\%), with an incidence of 2.5 (95\% CI: 1.9, 3.0) per 100 person-year (Fig. 3; 
Table 1 Baseline patient characteristics

\begin{tabular}{|c|c|c|c|c|c|}
\hline & $\begin{array}{l}\text { All patients } \\
\mathrm{N}=729\end{array}$ & $\begin{array}{l}\text { NYHA I } \\
N=306\end{array}$ & $\begin{array}{l}\text { NYHA II } \\
\mathrm{N}=309\end{array}$ & $\begin{array}{l}\text { NYHA III or IV } \\
N=114\end{array}$ & $p$ \\
\hline Age (yrs) & $76(67,84)$ & $74(66,83)$ & $77(68,85)$ & $77(69,84)$ & 0.107 \\
\hline Women & $292(40.1)$ & $139(45.4)$ & $116(37.5)$ & $37(32.5)$ & 0.027 \\
\hline Caucasian & $679(93.1)$ & $287(93.8)$ & $289(93.5)$ & $103(90.4)$ & 0.435 \\
\hline Body mass index $\left(\mathrm{kg} / \mathrm{m}^{2}\right)$ & $27.7(24.5,32.2)$ & $28.0(24.8,32.3)$ & $27.9(24.5,32.2)$ & $26.8(23.7,31.9)$ & 0.290 \\
\hline Hypertension & $585(80.2)$ & $236(77.1)$ & $251(81.2)$ & $98(86.0)$ & 0.110 \\
\hline Diabetes & $236(32.4)$ & $81(26.5)$ & $112(36.2)$ & $43(37.7)$ & 0.014 \\
\hline Dyslipidemia & $520(71.3)$ & $201(65.7)$ & $240(77.7)$ & $79(69.3)$ & 0.004 \\
\hline Current smoking & $68(9.3)$ & $28(9.2)$ & $29(9.4)$ & $11(9.6)$ & 0.987 \\
\hline Coronary artery disease & $365(50.1)$ & $101(33.0)$ & $196(63.4)$ & $68(59.6)$ & $<0.001$ \\
\hline Prior myocardial infarction & $197(27.0)$ & $32(10.5)$ & $114(36.9)$ & $51(44.7)$ & $<0.001$ \\
\hline Prior $\mathrm{PCl}$ & $216(29.6)$ & $61(19.9)$ & $118(38.2)$ & $37(32.5)$ & $<0.001$ \\
\hline Prior CABG & $138(18.9)$ & $30(9.8)$ & $79(25.6)$ & $29(25.4)$ & $<0.001$ \\
\hline Atrial fibrillation or flutter & $286(39.2)$ & $91(29.7)$ & $134(43.4)$ & $61(53.5)$ & $<0.001$ \\
\hline Stroke or TIA & $128(17.6)$ & $48(15.7)$ & $52(16.8)$ & $28(24.6)$ & 0.095 \\
\hline Chronic lung disease & $146(20.0)$ & $40(13.1)$ & $74(23.9)$ & $32(28.1)$ & $<0.001$ \\
\hline $\mathrm{O}_{2}$-dependent & $31(4.3)$ & $8(2.6)$ & $17(5.5)$ & $6(5.3)$ & 0.163 \\
\hline Peripheral artery disease & $121(16.6)$ & $37(12.1)$ & $63(20.4)$ & $21(18.4)$ & 0.018 \\
\hline CKD stage $\geq I \|$ & $207(28.6)$ & $45(14.8)$ & $109(35.5)$ & $53(46.9)$ & $<0.001$ \\
\hline Dialysis & $28(3.8)$ & $4(1.3)$ & $13(4.2)$ & $11(9.6)$ & 0.001 \\
\hline Anemia & $350(48.0)$ & $120(39.2)$ & $152(49.2)$ & $78(68.4)$ & $<0.001$ \\
\hline Permanent pacemaker & $101(13.9)$ & $18(5.9)$ & $60(19.4)$ & $23(20.2)$ & $<0.001$ \\
\hline Implanted defibrillator & $70(9.6)$ & $11(3.6)$ & $32(10.4)$ & $27(23.7)$ & $<0.001$ \\
\hline Severe liver cirrhosis & $2(0.3)$ & $0(0)$ & $1(0.3)$ & $1(0.9)$ & 0.288 \\
\hline Severe dementia & $4(0.5)$ & $0(0)$ & $1(0.3)$ & $3(2.6)$ & 0.013 \\
\hline Life-threatening malignancy & $18(2.5)$ & $9(2.9)$ & $7(2.3)$ & $2(1.8)$ & 0.809 \\
\hline Excessive frailty & $25(3.4)$ & $4(1.3)$ & $13(4.2)$ & $8(7.0)$ & 0.006 \\
\hline \multicolumn{6}{|l|}{ Medical therapy } \\
\hline Anti-platelet & $527(72.3)$ & $203(66.3)$ & $233(75.4)$ & $91(79.8)$ & 0.006 \\
\hline Warfarin or NOAC & $203(27.8)$ & $61(19.9)$ & $97(31.4)$ & $45(39.5)$ & $<0.001$ \\
\hline ACE-i or ARB & $404(55.4)$ & $141(46.1)$ & $193(62.5)$ & $70(61.4)$ & $<0.001$ \\
\hline Beta-blocker & $511(70.1)$ & $172(56.2)$ & $239(77.3)$ & $100(87.7)$ & $<0.001$ \\
\hline Nitrates & $83(11.4)$ & $19(6.2)$ & $38(12.3)$ & $26(22.8)$ & $<0.001$ \\
\hline Diuretic & $379(52.0)$ & $118(38.6)$ & $176(57.0)$ & 85 (74.6) & $<0.001$ \\
\hline Aldosterone antagonist & $54(7.4)$ & $11(3.6)$ & $22(7.1)$ & $21(18.4)$ & $<0.001$ \\
\hline
\end{tabular}

Data are reported as median (IQR) or no. (\%). ACE-i, angiotensin converting enzyme inhibitor; ARB, angiotensin receptor antagonist; CABG, coronary artery bypass grafting; CKD, chronic kidney disease; PCl, percutaneous coronary intervention; NOAC, novel oral anticoagulant; NYHA, New York Heart Association; TIA, transient ischemic attack

Table 3). The median time to AVR for these patients was 4.4 years (IQR: 1.9 to 7.9 years).

Survivorship analyses were similar with and without censoring for occurrence of AVR in follow-up. Overall, the 5-year survival and survival free of the combined endpoint of death or HF hospitalization were $52.7 \%$ (95\% CI: $49.0 \%$ to $56.4 \%$ ) and $43.5 \%$ (95\% CI: $39.8 \%$ to $47.2 \%$ ) with censoring for AVR, respectively. For the patients who had minimal or no symptoms (i.e., NYHA class I), these estimates were $66.4 \%$ (95\% CI: $60.9 \%$ to $71.9 \%$ ) and $57.3 \%$ (95\% CI: $51.6 \%$ to $63.0 \%$ ), respectively. Similarly, the survivorship was unchanged in a subset of patients without severe co-morbidities and with censoring for occurrence of AVR, with a 5-year survival of $58.0 \%$ (95\% CI: $54.1 \%$ to $61.9 \%$ ) (Fig. 4). For patients without futility markers and who had minimal or no symptoms, the estimate survival with censoring for AVR was 70.8\% (95\% CI: $65.3 \%$ to $76.3 \%$ ) (Fig. 4). Moreover, for patients with minimal or no symptoms, no potential futility markers, and preserved LV function, the 5-year survival with censoring for AVR was $72.0 \%$ (95\% CI: 66.3-77.7\%) (Additional file 1: Figure 2). For the combined endpoint of death or HF hospitalization, this survival was $61.7 \%$ (95\% CI: $55.6-67.8 \%$ ). 
Table 2 Echocardiographic data

\begin{tabular}{|c|c|c|c|c|c|}
\hline & $\begin{array}{l}\text { All patients } \\
\mathrm{N}=729\end{array}$ & $\begin{array}{l}\text { NYHA I } \\
N=306\end{array}$ & $\begin{array}{l}\text { NYHA II } \\
N=309\end{array}$ & $\begin{array}{l}\text { NYHA III or IV } \\
\mathrm{N}=114\end{array}$ & $p$ \\
\hline Peak aortic velocity (m/s) & $2.1(1.7,2.6)$ & $2.3(1.9,2.8)$ & $2.0(1.6,2.3)$ & $1.8(1.5,2.2)$ & $<0.001$ \\
\hline Mean aortic gradient $(\mathrm{mmHg})$ & $9.1(5.9,14.0)$ & $11.8(7.6,16.5)$ & $8.0(5.3,11.8)$ & $6.4(4.4,11.1)$ & $<0.001$ \\
\hline Aortic valve area $\left(\mathrm{cm}^{2}\right)$ & $1.51(1.34,1.73)$ & $1.48(1.30,1.70)$ & $1.55(1.37,1.74)$ & $1.57(1.38,1.75)$ & 0.004 \\
\hline Aortic valve area index $\left(\mathrm{cm}^{2} / \mathrm{m}^{2}\right)$ & $0.79(0.69,0.89)$ & $0.76(0.68,0.86)$ & $0.80(0.71,0.91)$ & $0.79(0.70,0.90)$ & 0.002 \\
\hline Dimensionless index & $0.44(0.39,0.47)$ & $0.43(0.38,0.47)$ & $0.44(0.40,0.47)$ & $0.44(0.38,0.48)$ & 0.196 \\
\hline Stroke volume index $\left(\mathrm{ml} / \mathrm{m}^{2}\right)$ & $33.8(25.6,41.2)$ & $37.1(30.0,44.3)$ & $31.4(25.1,39.5)$ & $28.2(23.0,36.0)$ & $<0.001$ \\
\hline Stroke volume index $<35 \mathrm{ml} / \mathrm{m}^{2}$ & $357(54.3)$ & $104(38.5)$ & $178(62.7)$ & $75(72.1)$ & $<0.001$ \\
\hline Left ventricular EDD (cm) & $4.8(4.2,5.4)$ & $4.5(4.0,5.1)$ & $4.8(4.2,5.4)$ & $5.4(4.9,6.0)$ & $<0.001$ \\
\hline Left ventricular mass index $\left(\mathrm{g} / \mathrm{m}^{2}\right)$ & $112(91,137)$ & $101(83,124)$ & $116(96,139)$ & $132(108,161)$ & $<0.001$ \\
\hline Left ventricular ejection fraction (\%) & $58(45,63)$ & $60(58,65)$ & $55(40,63)$ & $38(23,58)$ & $<0.001$ \\
\hline Left ventricular ejection fraction $<50 \%$ & $207(28.4)$ & $23(7.5)$ & $112(36.2)$ & $72(63.2)$ & $<0.001$ \\
\hline$E / e^{\prime}$ & $12.0(9.0,16.0)$ & $11.0(8.5,15.0)$ & $12.0(9.0,17.0)$ & $13.0(10.9,18.0)$ & 0.006 \\
\hline Left atrial volume index $\left(\mathrm{ml} / \mathrm{m}^{2}\right)$ & $37(29,49)$ & $34(27,46)$ & $36(29,50)$ & $45(34,56)$ & $<0.001$ \\
\hline RV systolic pressure (mmHg) & $35(28,44)$ & $33(27,40)$ & $36(28,46)$ & $43(36,51)$ & $<0.001$ \\
\hline$\geq$ moderate MR & $61(8.4)$ & $10(3.3)$ & $34(11.1)$ & $17(14.9)$ & $<0.001$ \\
\hline$\geq$ moderate TR & $96(13.5)$ & $31(10.4)$ & $38(12.7)$ & $27(24.3)$ & 0.001 \\
\hline$\geq$ moderate RV dysfunction & $33(4.7)$ & $2(0.7)$ & $13(4.3)$ & $18(16.8)$ & $<0.001$ \\
\hline
\end{tabular}

Data are reported as median (IQR) or no. (\%). EDD, end-diastolic dimension; LV, left ventricle; MR, mitral regurgitation; NYHA, New York Heart Association; RV, right ventricular; TR, tricuspid regurgitation

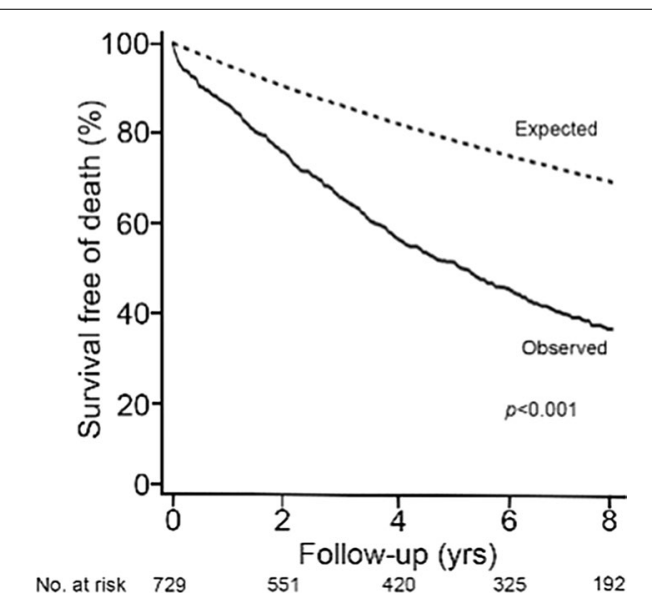

Fig. 1 Survival of patients with moderate aortic stenosis. Observed survival free of all-cause mortality (solid) for the entire study cohort in comparison to the expected survival, based on the age- and sex-matched total Minnesota population (dashed), is shown

\section{Multivariate models}

In univariate and survival analyses, traditional prognostic echocardiographic parameters (e.g., LV ejection fraction $<50 \%$, stroke volume index $<35 \mathrm{ml} / \mathrm{m}^{2}$, and rapid AS progression rate $[\operatorname{Vmax}>0.3 \mathrm{~m} / \mathrm{s} / \mathrm{y}]$ ) were associated with worse outcomes in this cohort of patients (Additional file 1: Figures 3-5). In multivariate models, age, NYHA functional class, low LV ejection fraction and high peak aortic velocity were associated with all-cause mortality with AVR modeled as a time-dependent variable
(Table 4). These associations were present in analyses of the overall population, as well as in analyses that excluded patients with potential futility markers (Table 4). These same variables were also independently associated with the occurrence of the composite endpoint of death or HF hospitalization in patients with or without potential futility markers (Table 4).

\section{Discussion}

The present investigation is a real-world examination of outcomes in patients with moderate AS evaluated in a large health system that includes outpatient care clinics and tertiary referral centers. The principal findings are: (1) Patients with moderate AS can have impaired prognosis, with a 5 -year survival only $52 \%$ observed in this study; (2) The heightened risk of death remains even when focusing on patients with minimal or no symptoms, no LV systolic dysfunction and no potential futility markers, in whom the 5 -year survival was only $72 \%$; (3) These outcomes were observed while there were low rates of progression to severe AS ( $4 \%$ per year) and need for AVR ( $\sim 2.5 \%$ per year), and after accounting for the occurrence of such events with censoring; (4) Advanced age, worse NYHA functional class, low ejection fraction, high peak aortic velocity and severe comorbidities were associated with worse outcomes. Taken together, these findings highlight the prognostic impact of AS, even when only moderate in severity. 
Table 3 Major adverse clinical events

\begin{tabular}{|c|c|c|c|c|c|}
\hline All patients & $\begin{array}{l}\text { Overall } \\
\mathrm{N}=729\end{array}$ & $\begin{array}{l}\text { NYHA I } \\
N=306\end{array}$ & $\begin{array}{l}\text { NYHA II } \\
N=309\end{array}$ & $\begin{array}{l}\text { NYHA III or IV } \\
N=114\end{array}$ & $P$ \\
\hline Any death & $12.6(11.4,13.7)$ & $7.9(6.6,9.2)$ & $15.1(13.1,17.1)$ & $25.2(20.2,30.3)$ & $<0.001$ \\
\hline Heart failure hospitalization & $6.7(5.8,7.6)$ & $4.5(3.4,5.5)$ & $7.9(6.3,9.4)$ & $13.9(9.8,18.1)$ & 0.014 \\
\hline Any death or heart failure hospitalization & $16.3(14.9,17.7)$ & $10.7(9.2,12.3)$ & $19.5(17.0,22.0)$ & $33.4(26.9,39.8)$ & $<0.001$ \\
\hline Progression to severe aortic stenosis* & $3.9(3.1,4.7)$ & $4.3(3.1,5.5)$ & $3.5(2.3,4.7)$ & $3.2(0.8,5.5)$ & 0.014 \\
\hline AVR & $2.5(1.9,3.0)$ & $3.0(2.2,3.9)$ & $1.9(1.2,2.7)$ & $1.9(0.5,3.4)$ & 0.001 \\
\hline Any death, heart failure hospitalization, or AVR & $18.4(16.9,20.0)$ & $13.1(11.3,15.0)$ & $21.1(18.5,23.7)$ & $35.4(28.7,42.2)$ & $<0.001$ \\
\hline Myocardial infarction & $2.3(1.8,2.8)$ & $1.5(0.9,2.1)$ & $3.6(2.5,4.6)$ & $1.3(0.2,2.5)$ & 0.002 \\
\hline Stroke & $2.0(1.5,2.5)$ & $1.8(1.2,2.5)$ & $2.1(1.3,2.8)$ & $2.8(1.0,4.5)$ & 0.824 \\
\hline Patients without severe morbidities & $\begin{array}{l}\text { Overall } \\
N=639\end{array}$ & $\begin{array}{l}\text { NYHA I } \\
N=283\end{array}$ & $\begin{array}{l}\text { NYHA II } \\
N=267\end{array}$ & $\begin{array}{l}\text { NYHA III or IV } \\
\mathrm{N}=89\end{array}$ & $P$ \\
\hline Any death & $10.8(9.7,12.0)$ & $7.0(5.8,8.2)$ & $13.0(11.0,14.9)$ & $23.2(17.8,28.5)$ & $<0.001$ \\
\hline Heart failure hospitalization & $6.2(5.4,7.1)$ & $4.4(3.3,5.4)$ & $7.2(5.7,8.8)$ & $13.6(9.1,18.1)$ & 0.018 \\
\hline Any death or heart failure hospitalization & $14.3(13.0,15.7)$ & $9.8(8.2,11.3)$ & $16.9(14.6,19.3)$ & $30.7(24.0,37.5)$ & $<0.001$ \\
\hline Progression to severe aortic stenosis & $3.9(3.0,4.7)$ & $4.4(3.2,5.6)$ & $3.3(2.1,4.5)$ & $3.2(0.6,5.7)$ & 0.012 \\
\hline AVR & $2.5(1.9,3.0)$ & $3.1(2.2,3.9)$ & $1.9(1.1,2.6)$ & $2.0(0.4,3.6)$ & 0.003 \\
\hline Any death, heart failure hospitalization, or AVR & $16.4(14.9,17.9)$ & $12.1(10.4,13.9)$ & $18.5(15.9,21.0)$ & $33.1(25.9,40.3)$ & $<0.001$ \\
\hline Myocardial infarction & $2.2(1.7,2.7)$ & $1.4(0.9,2.0)$ & $3.5(2.5,4.6)$ & $1.3(0.03,2.6)$ & 0.002 \\
\hline Stroke & $2.0(1.5,2.5)$ & $1.9(1.2,2.6)$ & $1.9(1.1,2.6)$ & $3.0(1.0,5.0)$ & 0.657 \\
\hline
\end{tabular}

Rates are reported as events per 100 person-year follow-up with $95 \%$ confidence intervals. ${ }^{*}$ Overall, 517 patients (71 \%) had echocardiography in follow-up. $P$ value was calculated using the chi-square test or Fisher's exact test. AVR, aortic valve replacement; NYHA, New York Heart Association

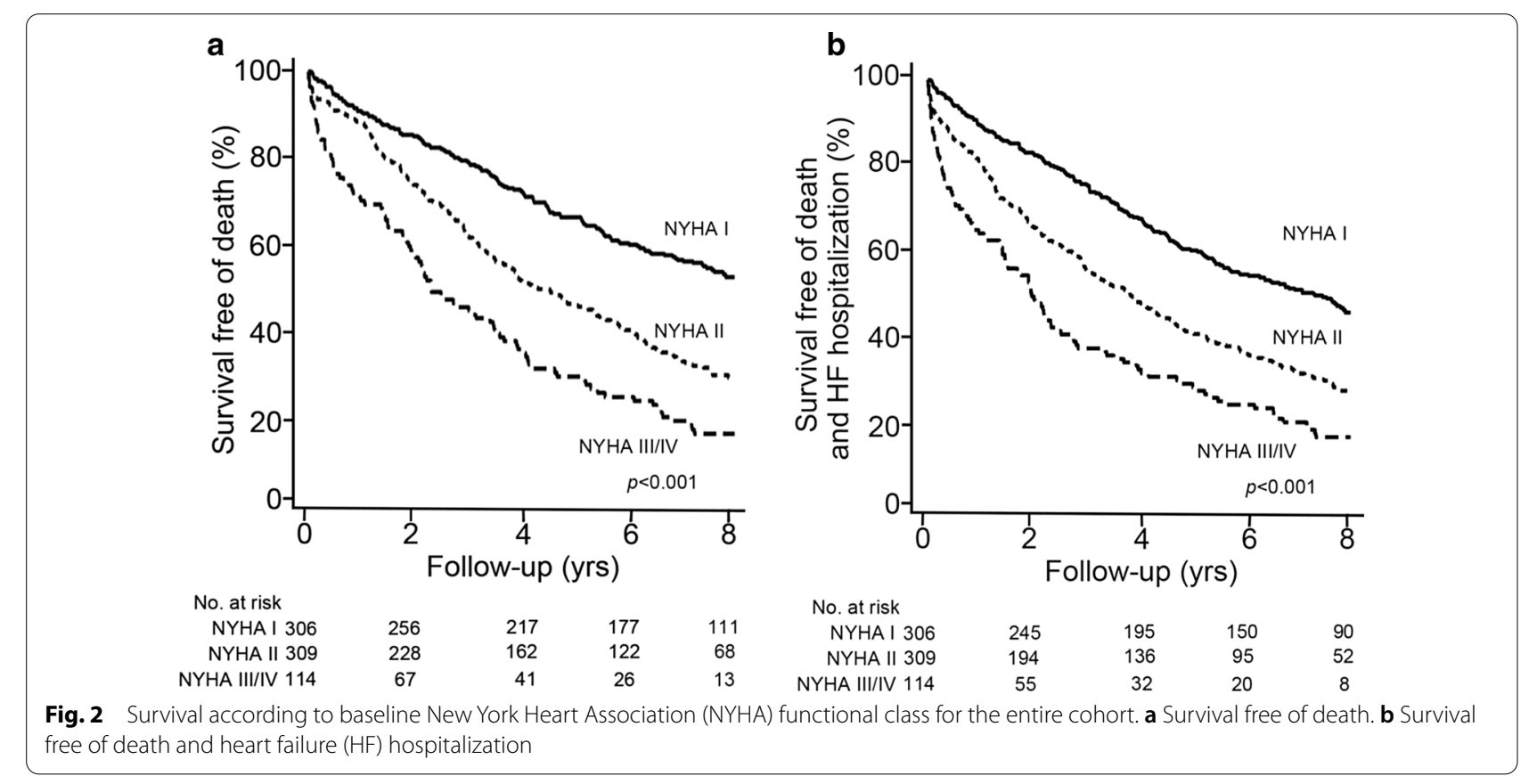

While there has been intense focus on the evaluation and management of patients with severe AS, those with moderate disease may be vulnerable with an impaired prognosis. The present investigation was undertaken as a real-world, longitudinal study of 729 patients with moderate AS (median AVA, $1.5 \mathrm{~cm}^{2}$ ) observed over a median follow-up of 5.0 years. In our study, the 5 -year survival was $52 \%$ for the entire cohort. Hospitalization 
a
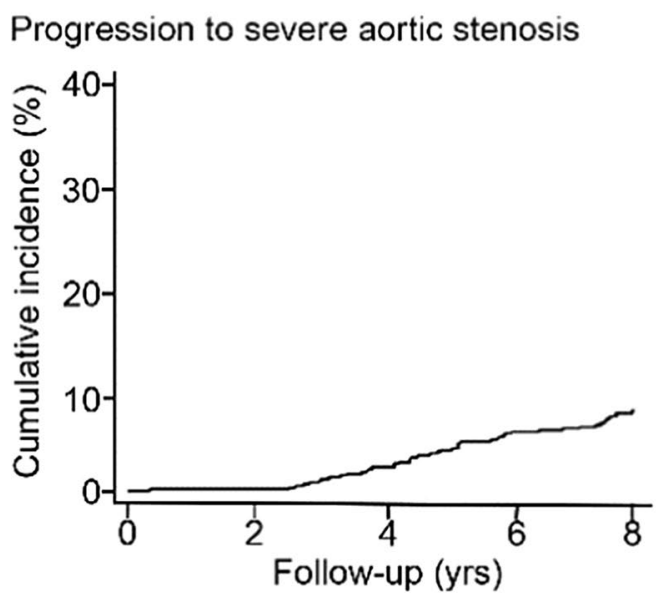

b

Progression to aortic valve replacement

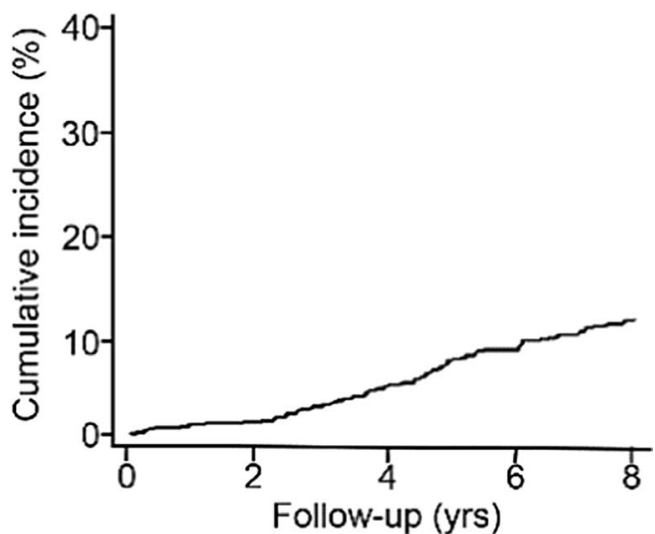

Fig. 3 Disease progression for patients with moderate aortic stenosis. a Incidence of disease progression to severe aortic stenosis among patients with echocardiography in follow-up $(n=517)$. $\mathbf{b}$ Incidence of aortic valve replacement in the entire cohort $(n=729)$

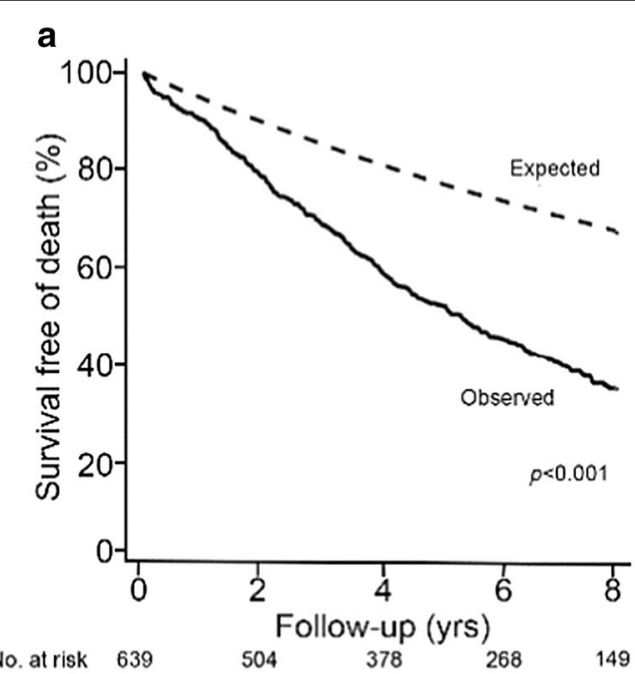

\section{b}

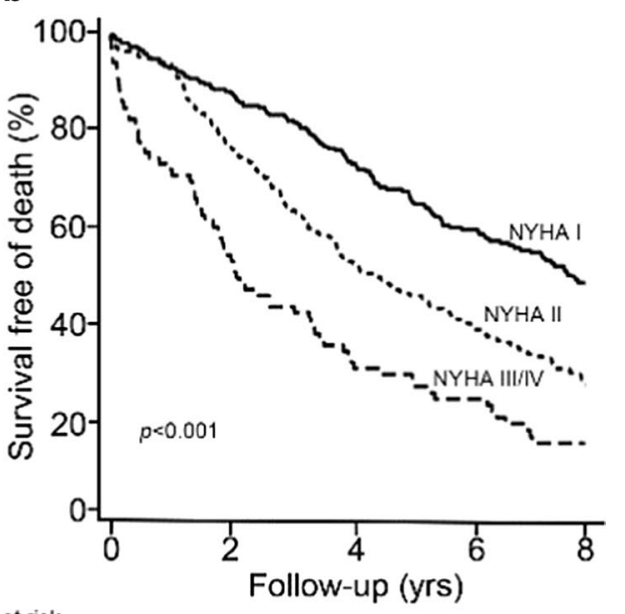

$\begin{array}{rrrrrr}\text { No. at risk } & & & & & \\ \text { NYHAI } & 283 & 245 & 199 & 142 & 81 \\ \text { NYHA II } & 267 & 208 & 147 & 105 & 57 \\ \text { NYHA IIIIIV } & 89 & 51 & 32 & 21 & 11\end{array}$

Fig. 4 Survival in patients with moderate aortic stenosis who were without severe morbidities, with survival times censored at aortic valve replacement $(\mathrm{N}=639)$. a Observed survival (solid) in comparison to the expected survival based on the age- and sex-matched total Minnesota population (dashed). b Observed survival according to New York Heart Association (NYHA) functional class

for HF occurred at rate of $\sim 6.0 \%$ per year. Certainly, this survivorship is better than what would be expected for severe, symptomatic aortic stenosis, where the mortality rates are commonly $25 \%$ per year or more [7]. Nevertheless, the annual mortality rate of $12.6 \%$ in our study is notable, and markedly worse than expected. Our findings mirror the results of Strange et al. [7], who utilized a large national echocardiography database in Australia and reported a 5-year mortality rate of $56 \%$ for 3,315 patients with moderate AS. Similarly, in a separate study of 508 moderate AS patients by Delesalle et al., the 6-year survival was only $53 \%$ [8]. Taken together, the risk of death in patients with moderate AS is remarkable, and deserves further scrutiny regarding potential management to improve their prognosis.

Importantly, our findings extend the results of other studies, with a more granular analysis of the influence of symptoms, LV systolic function, occurrence of AVR, and morbidities on survival of these patients. Not surprisingly, worse functional class was strongly associated 
Table 4 Multivariate models. Cox proportional hazard regression analyses for predicting outcomes are shown

\begin{tabular}{|c|c|c|c|c|c|c|c|c|c|c|c|c|}
\hline \multirow[t]{3}{*}{ Variables } & \multirow{2}{*}{\multicolumn{3}{|c|}{$\begin{array}{l}\text { All patients } \\
\text { Any death }\end{array}$}} & \multicolumn{9}{|c|}{ Patients without severe morbidities } \\
\hline & & & & \multicolumn{3}{|c|}{$\begin{array}{l}\text { Any death/HF } \\
\text { hospitalization }\end{array}$} & \multicolumn{3}{|c|}{ Any death } & \multicolumn{3}{|c|}{$\begin{array}{l}\text { Any death/HF } \\
\text { hospitalization }\end{array}$} \\
\hline & HR & $95 \% \mathrm{Cl}$ & $p$ value & HR & $95 \% \mathrm{Cl}$ & $p$ value & HR & $95 \% \mathrm{Cl}$ & $p$ value & HR & $95 \% \mathrm{Cl}$ & $p$ value \\
\hline Age (per 1-year) & 1.04 & $1.03-1.05$ & $<0.001$ & 1.03 & $1.02-1.05$ & $<0.001$ & 1.05 & $1.04-1.06$ & $<0.001$ & 1.04 & $1.03-1.05$ & $<0.001$ \\
\hline BSA (per $\left.1 \mathrm{~kg} / \mathrm{m}^{2}\right)$ & 0.50 & $0.29-0.85$ & 0.010 & 0.60 & $0.37-0.98$ & 0.041 & - & - & - & - & - & - \\
\hline Occurrence of AVR* & 0.77 & $0.49-1.19$ & 0.237 & 1.00 & $0.63-1.57$ & 0.986 & 0.86 & $0.54-1.36$ & 0.510 & 0.89 & $0.55-1.45$ & 0.643 \\
\hline NYHA II & 1.39 & $1.09-1.76$ & 0.007 & 1.37 & $1.10-1.70$ & 0.005 & 1.37 & $1.06-1.78$ & 0.016 & 1.29 & $1.02-1.64$ & 0.034 \\
\hline NYHA III or IV & 1.67 & $1.20-2.31$ & 0.002 & 1.38 & $1.01-1.90$ & 0.045 & 1.72 & $1.20-2.47$ & 0.003 & 1.45 & $1.02-2.04$ & 0.036 \\
\hline Stroke/TIA & 1.44 & $1.14-1.83$ & 0.002 & 1.32 & $1.05-1.66$ & 0.016 & 1.58 & $1.22-2.03$ & $<0.001$ & 1.37 & $1.07-1.75$ & 0.012 \\
\hline Hypertension & - & - & - & 1.41 & $1.10-1.82$ & 0.007 & - & - & - & 1.35 & $1.03-1.78$ & 0.031 \\
\hline Diabetes & 1.25 & $1.01-1.54$ & 0.039 & 1.24 & $1.02-1.52$ & 0.030 & - & - & - & 1.26 & $1.01-1.57$ & 0.040 \\
\hline Chronic lung disease & 1.53 & $1.22-1.91$ & $<0.001$ & 1.35 & $1.09-1.68$ & 0.007 & 1.52 & $1.17-1.96$ & 0.002 & 1.44 & $1.12-1.85$ & 0.004 \\
\hline CKD stage $\geq I I I$ & 1.43 & $1.16-1.77$ & 0.001 & 1.24 & $1.00-1.53$ & 0.046 & 1.41 & $1.12-1.78$ & 0.003 & 1.33 & $1.06-1.67$ & 0.014 \\
\hline Anemia & 1.60 & $1.30-1.98$ & $<0.001$ & 1.50 & $1.23-1.83$ & $<0.001$ & 1.64 & $1.32-2.04$ & $<0.001$ & 1.45 & $1.18-1.79$ & 0.001 \\
\hline Liver cirrhosis & 3.36 & $1.75-6.45$ & $<0.001$ & 2.70 & $1.41-5.15$ & 0.003 & 3.48 & $1.68-7.22$ & $<0.001$ & 2.22 & $1.07-4.59$ & 0.032 \\
\hline Dementia & 1.85 & $1.31-2.61$ & $<0.001$ & 1.77 & $1.27-2.46$ & 0.001 & 1.98 & $1.33-2.95$ & $<0.001$ & 1.59 & $1.07-2.35$ & 0.022 \\
\hline Malignancy & 11.75 & $6.89-20.06$ & $<0.001$ & 7.57 & $4.50-12.73$ & $<0.001$ & - & - & - & - & - & - \\
\hline Excessive frailty & 2.38 & $1.51-3.76$ & $<0.001$ & 2.90 & $1.85-4.56$ & $<0.001$ & - & - & - & - & - & - \\
\hline LV ejection fraction (per 1\%) & 0.98 & $0.98-0.99$ & 0.001 & 0.98 & $0.97-0.99$ & $<0.001$ & 0.98 & $0.97-0.99$ & 0.002 & 0.97 & $0.97-0.98$ & $<0.001$ \\
\hline Peak aortic velocity (per $1 \mathrm{~m} / \mathrm{s}$ ) & 1.37 & $1.13-1.67$ & 0.002 & 1.37 & $1.14-1.64$ & 0.001 & 1.34 & $1.08-1.67$ & 0.008 & 1.39 & $1.14-1.70$ & 0.001 \\
\hline$\geq$ moderate TR & 1.47 & $1.13-1.92$ & 0.005 & 1.32 & $1.01-1.72$ & 0.041 & 1.47 & $1.09-1.98$ & 0.012 & 1.43 & $1.08-1.91$ & 0.014 \\
\hline$\geq$ moderate RV dysfunction & 2.58 & $1.61-4.16$ & $<0.001$ & 2.03 & $1.27-3.24$ & 0.003 & 2.59 & $1.46-4.60$ & 0.001 & 1.73 & $1.00-2.99$ & 0.051 \\
\hline
\end{tabular}

*AVR as a time-dependent variable. AVR, aortic valve replacement; $\mathrm{BSA}$, body mass index; $\mathrm{Cl}$, confidence interval; $\mathrm{CKD}$, chronic kidney disease; HF, heart failure; HR, hazard ratio; LV, left ventricular; NYHA, New York Heart Association; RV, right ventricular; SV, stroke volume; TIA, transient ischemic attack; TR, tricuspid regurgitation

with the presence of morbidities and poor survival, with an annual mortality rate of $25 \%$ for those with most impairment (i.e., NYHA III/IV), and many morbidities were independently predictive of the long-term outcomes. Nonetheless, for those patients with minimal or no symptoms and with no evidence of futility, the 5-year survival was still only $71 \%$ with an annualized death rate of $\sim 7.0 \%$ per year. This survivorship also was similar when we restricted analyses to those patients with minimal impairment, who had preserved LV function and no futility markers, with and without censoring for occurrence of AVR (i.e., 5-year survival free of all-cause mortality, 72\%).

While a study of a younger population of patients with moderate AS $(n=514)$ by Lancelotti et al. [4] found a 4-year survival of $89 \%$, it is recognized that AS, even when not severe, can impart significant myocardial architectural changes. Increases in LV mass, mid-wall fibrosis, and extracellular volume can occur with progression of AS, even when not severe [18-22]. As reversibility of cardiac damage with AVR has been shown in severe AS, there is rationale for consideration of AVR in patients with moderate AS and LV dysfunction [23-26]. Whether such therapy should be extended to all patients with moderate AS, with or without preserved LV function, may be a consideration. The high mortality rate in our study, as has been observed in others, invites scrutiny into the possible benefit of AVR in patients with preserved LV function and with minimal clinical impairment, especially given that procedural mortality with modern transcatheter or surgical techniques is now relatively low, and often $<1-3 \%$ [27]. Certainly, a survival benefit of such therapy for patients with moderate AS would only be hypothetical until tested in prospective, randomized clinical trials [28].

The present study was a longitudinal, yet retrospective analysis of patients from hospitals and outpatient clinics, therefore subject to selection bias. Nonetheless, our findings suggest the need for close clinical follow-up and better clinical management in patients with moderate AS, who are at significant risk of death, even when minimally or asymptomatic. A single positive echocardiographic parameter for defining moderate AS also posed limitations. In addition, in the cohort of patients with no symptoms, no severe morbidities, and preserved LV function, some patients with a prior history of myocardial infarction were included and that morbidity could have impacted their survival. Lastly, we were limited in our 
ability to adjudicate cardiovascular from non-cardiovascular deaths, which would be important to determine a potential protective role for AVR.

\section{Conclusions}

Our study demonstrates significant mortality rates for patients with moderate AS in the setting of hospital and outpatient clinic, and thus highlights the need to reexamine thresholds for clinical surveillance and intervention in patients with moderate AS.

\section{Supplementary Information}

The online version contains supplementary material available at https://doi. org/10.1186/s12872-021-01901-1.

Addititional file 1. Figure 1 Study flow-chart. AVA, aortic valve area; AS, aortic stenosis; F/U, follow up. Figure $\mathbf{2}$ Survival of patients with moderate aortic stenosis who were without severe morbidities or left ventricular dysfunction, with survival times censored at aortic valve replacement ( $N=461$ ). (A) Observed survival in comparison to the expected survival based on the age- and sex-matched total Minnesota population. (B) Observed survival according to New York Heart Association (NYHA) functional class. Figure 3. Survival of patients with moderate aortic stenosis according to stroke volume index (SVi) $<35 \mathrm{ml} / \mathrm{m} 2 \mathrm{vs}$. $\geq 35 \mathrm{ml} /$ m2. (A) Observed survival free of death. (B) Observed survival free of death or heart failure (HF) hospitalization. Figure 4. Survival of patients with moderate aortic stenosis according to left ventricular ejection fraction $(\mathrm{EF})<50 \%$ vs. $\geq 50 \%$. (A) Observed survival free of death. (B) Observed survival free of death or heart failure (HF) hospitalization. Figure 5. Survival of patients with moderate aortic stenosis according to rate of aortic stenosis progression ( $\operatorname{Vmax}>0.3 \mathrm{~m} / \mathrm{s} / \mathrm{y}$ vs. $\leq 0.3 \mathrm{~m} / \mathrm{s} / \mathrm{y})$ in patients with available echocardiographic follow-up ( $N=505)$. (A) Observed survival free of death. (B) Observed survival free of death or heart failure (HF) hospitalization.

\section{Abbreviations}

AS: aortic stenosis; AVR: aortic valve replacement; AVA: aortic valve area; $\mathrm{Cls}$ : confidence intervals; DI: dimensionless index; HF: heart failure; IQR: interquartile range; LV: left ventricular; MI: myocardial infarction; NYHA: New York Heart Association; $\mathrm{VTI}$ : velocity time integral.

\section{Acknowledgements}

Not applicable.

\section{Authors' contributions}

YD, MG, SG, JLC and PS designed and prepared the study concept. YD, CS, LS and RG analyzed the data. YD, GH, MF, BL, AA and PS drafted the manuscript with advice from MES, MG, SG, RB, SMB and RS. All authors gave their final approval for the manuscript being published and agreed to be accountable for all aspects of the work. All authors read and approved the final manuscript.

\section{Funding}

This study was not funded.

\section{Availability of data and materials}

The datasets used and/or analysed during the current study are available from the corresponding author on reasonable request.

\section{Ethics approval and consent to participate}

The study was approved by the Allina Institutional Review Board and was performed in accordance with the Declaration of Helsinki. Written consent to participate was obtained from study participants.
Consent for publication

Not required.

\section{Competing interests}

Dr. Gössl serves as a consultant for Abbott Structural. Dr. Garcia receives Institutional Research grants from Edwards Lifesciences and Boston Scientific; proctors Edwards Lifesciences. Dr. Sarano is a consultant for Cryolife inc, Edwards Lifesciences LLC. Dr. Cavalcante serves as a consultant for Boston Scientific, Abbott Vascular; a speaker for Medtronic, Circle Cardiovascular Imaging, and Siemens Healthineers; receives research grant support from Circle Cardiovascular Imaging, Edwards Lifesciences, Medtronic, Boston Scientific, and Abbott Vascular. Dr. Bae is a consultant for Abbott Structural. Dr. Sorajja is a consultant for Abbott Structural, Anteris, Boston Scientific, Edwards Lifesciences, Medtronic, TeleFlex, WL Gore. The other authors report no conflict of interest.

\section{Author details}

${ }^{1}$ Roger L. and Lynn C. Headrick Chair, Valve Science Center, Minneapolis Heart Institute Foundation, Abbott Northwestern Hospital, Minneapolis, MN 55407, USA. ${ }^{2}$ Department of Cardiology, Beijing Anzhen Hospital, Capital Medical University, Beijing 100029, China.

Received: 9 October 2020 Revised: 30 January 2021 Accepted: 2 February 2021

Published online: 19 February 2021

\section{References}

1. Nkomo VT, Gardin JM, Skelton TN, Gottdiener JS, Scott CG, EnriquezSarano M. Burden of valvular heart diseases: a population-based study. Lancet (Lond, Engl). 2006;368:1005-11.

2. Nishimura RA, Otto CM, Bonow RO, Carabello BA, Erwin JP 3rd, Guyton RA, O'Gara PT, Ruiz CE, Skubas NJ, Sorajja P, Sundt TM 3rd, Thomas JD. 2014 AHA/ACC guideline for the management of patients with valvular heart disease: executive summary: a report of the American College of Cardiology/American Heart Association Task Force on Practice Guidelines. J Am Coll\&nbsp; Cardiol. 2014;63:2438-88.

3. Baumgartner H, Falk V, Bax JJ, De Bonis M, Hamm C, Holm PJ, lung B, Lancellotti P, Lansac E, Rodriguez Munoz D, Rosenhek R, Sjogren J, Tornos Mas P, Vahanian A, Walther T, Wendler O, Windecker S, Zamorano JL. 2017 ESC/EACTS Guidelines for the management of valvular heart disease. Eur Heart J. 2017;38:2739-91.

4. 4, Lancellotti P, Magne J, Dulgheru R, Clavel MA, Donal E, Vannan MA, Chambers J, Rosenhek R, Habib G, Lloyd G, Nistri S, Garbi M, Marchetta S, Fattouch K, Coisne A, Montaigne D, Modine T, Davin L, Gach O, Radermecker M, Liu S, Gillam L, Rossi A, Galli E, llardi F, Tastet L, Capoulade R, Zilberszac R, Vollema EM, Delgado V, Cosyns B, Lafitte S, Bernard A, Pierard LA, Bax JJ, Pibarot P, Oury C. Outcomes of patients with asymptomatic aortic stenosis followed up in heart valve clinics. JAMA Cardiol. 2018:3:1060-8

5. Bahler RC, Hawi R, Rovner A, Finkelhor RS, Thomas CL, Dawson NV. Predicting outcomes in patients with asymptomaticmoderate to severe aortic stenosis. Am J Cardiol. 2018;122:851-8.

6. Yechoor P, Blaustein AS, Bakaeen FG, Cornwell LD, Coselli JS, LeMaire SA, Chu D. The natural history of moderate aortic stenosis in a veteran population. J Thoracic Cardiovasc Surg. 2013;145:1550-3.

7. Strange G, Stewart S, Celermajer D, Prior D, Scalia GM, Marwick T, IIton M, Joseph M, Codde J, Playford D. Poor long-term survival in patients with moderate aortic stenosis. J Am Coll Cardiol. 2019;74:1851-63.

8. Delesalle G, Bohbot Y, Rusinaru D, Delpierre Q, Marechaux S, Tribouilloy C. Characteristics and prognosis of patients with moderate aortic stenosis and preserved left ventricular ejection fraction. J Am Heart Assoc. 2019:8:e011036.

9. van Gils L, Clavel MA, Vollema EM, Hahn RT, Spitzer E, Delgado V, Nazif T, De Jaegere PP, Geleijnse ML, Ben-Yehuda O, Bax JJ, Leon MB, Pibarot P, Van Mieghem NM. Prognostic implications of moderate aortic stenosis in patients with left ventricular systolic dysfunction. J Am Coll Cardiol. 2017;69:2383-92 
10. 10, Baumgartner H, Hung J, Bermejo J, Chambers JB, Edvardsen T, Goldstein S, Lancellotti P, LeFevre M, Miller F Jr, Otto CM. Recommendations on the echocardiographic assessment of aortic valve stenosis: a focused update from the european association of cardiovascular imaging and the american society of echocardiography. J Am Soc Echocardiogr. 2017;30:372-92.

11. Saikrishnan N, Kumar G, Sawaya FJ, Lerakis S, Yoganathan AP. Accurate assessment of aortic stenosis: a review of diagnostic modalities and hemodynamics. Circulation. 2014;129:244-53.

12. Devereux RB, Alonso DR, Lutas EM, Gottlieb GJ, Campo E, Sachs I, Reichek N. Echocardiographic assessment of left ventricular hypertrophy: comparison to necropsy findings. Am J Cardiol. 1986;57:450-8.

13. Niikura H, Gossl M, Kshettry V, Olson S, Sun B, Askew J, Stanberry L, Garberich R, Tang L, Lesser J, Bae R, Harris KM, Bradley SM, Sorajja P. Causes and clinical outcomes of patients who are ineligible for transcatheter mitral valve replacement. JACC Cardiovasc Intervent. 2019;12:196-204.

14. Lindman BR, Alexander KP, O'Gara PT, Afilalo J. Futility, benefit, and transcatheter aortic valve replacement. JACC Cardiovasc Intervent. 2014;7:707-16.

15. Tang L, Gossl M, Ahmed A, Garberich R, Bradley SM, Niikura H, Witt D, Pedersen WR, Bae R, Lesser JR, Harris KM, Sun B, Mudy K, Sorajja P. Contemporary reasons and clinical outcomes for patients with severe, symptomatic aortic stenosis not undergoing aortic valve replacement. Circulation Cardiovasc Intervent. 2018;11:e007220.

16. Kappetein AP, Head SJ, Genereux P, Piazza N, van Mieghem NM, Blackstone EH, Brott TG, Cohen DJ, Cutlip DE, van Es GA, Hahn RT, Kirtane AJ, Krucoff MW, Kodali S, Mack MJ, Mehran R, Rodes-Cabau J, Vranckx P, Webb JG, Windecker S, Serruys PW, Leon MB. Updated standardized endpoint definitions for transcatheter aortic valve implantation: the Valve Academic Research Consortium-2 consensus document. J Am Coll Cardiol. 2012:60:1438-54.

17. Leon MB, Piazza N, Nikolsky E, Blackstone EH, Cutlip DE, Kappetein AP, Krucoff MW, Mack M, Mehran R, Miller C, Morel MA, Petersen J, Popma JJ, Takkenberg JJ, Vahanian A, van Es GA, Vranckx P, Webb JG, Windecker S, Serruys PW. Standardized endpoint definitions for Transcatheter Aortic Valve Implantation clinical trials: a consensus report from the Valve Academic Research Consortium. J Am Coll Cardiol. 2011;57:253-69.

18. Everett RJ, Tastet L, Clavel MA, Chin CWL, Capoulade R, Vassiliou VS, Kwiecinski J, Gomez M, van Beek EJR, White AC, Prasad SK, Larose E, Tuck C, Semple S, Newby DE, Pibarot P, Dweck MR. Progression of hypertrophy and myocardial fibrosis in aortic stenosis: a multicenter cardiac magnetic resonance study. Circul Cardiovasc Imag. 2018:11:e007451.

19. Vassiliou VS, Perperoglou A, Raphael CE, Joshi S, Malley T, Everett R, Halliday B, Pennell DJ, Dweck MR, Prasad SK. Midwall fibrosis and 5-year outcome in moderate and severe aortic stenosis. J Am Coll Cardiol. 2017:69:1755-6.

20. Everett RJ, Treibel TA, Fukui M, Lee H, Rigolli M, Singh A, Bijsterveld P, Tastet L, Musa TA, Dobson L, Chin C, Captur G, Om SY, Wiesemann S, Ferreira VM, Piechnik SK, Schulz-Menger J, Schelbert EB, Clavel MA, Newby DE, Myerson SG, Pibarot P, Lee S, Cavalcante JL, Lee SP, McCann GP, Greenwood
JP, Moon JC, Dweck MR. Extracellular myocardial volume in patients with aortic stenosis. J Am Coll Cardiol. 2020;75:304-16.

21. Zhu D, Ito S, Miranda WR, Nkomo VT, Pislaru SV, Villarraga HR, Pellikka PA Crusan DJ, Oh JK. Left ventricular global longitudinal strain is associated with long-term outcomes in moderate aortic stenosis. Circul Cardiovasc Imag. 2020;13:e009958.

22. Hayward C, Thornton G, Asher A, Tyebally S, Ray-Chaudhuri A, Mangan C, Mouyis K, Harvey G, Saheecha S, Liu S, Singhal A, Karia N, Patel K, Lloyd $G$, Bhattacharyya S. Determinants of outcome in patients with left ventricular impairment and moderate aorticstenosis. JACC Cardiovasc Imag. 2020;13:1449-50.

23. Schreuder MBB, Daemen JJ, Van Mieghem JNM. Hemodynamic effects of transcatheter aortic valve replacement for moderate aortic stenosis with reduced left ventricular ejection fraction. JACC Cardiovasc Intervent. 2019;12:684-6.

24. Samad Z, Vora AN, Dunning A, Schulte PJ, Shaw LK, Al-Enezi F, Ersboll M, McGarrah RW 3rd, Vavalle JP, Shah SH, Kisslo J, Glower D, Harrison JK, Velazquez EJ. Aortic valve surgery and survival in patients with moderate or severe aortic stenosis and left ventricular dysfunction. Eur Heart J. 2016:37:2276-86.

25. Chau KH, Douglas PS, Pibarot P, Hahn RT, Khalique OK, Jaber WA, Cremer P, Weissman NJ, Asch FM, Zhang Y, Gertz ZM, Elmariah S, Clavel MA, Thourani VH, Daubert M, Alu MC, Leon MB, Lindman BR. Regression of Left ventricular mass after transcatheter aortic valve replacement: the PARTNER trials and registries. J Am Coll Cardiol. 2020;75:2446-58.

26. Eleid MF, Padang R, Pislaru SV, Greason KL, Crestanello J, Nkomo VT, Pellikka PA, Jentzer JC, Gulati R, Sandhu GS, Holmes DR Jr, Nishimura RA, Rihal CS, Borlaug BA. Effect of transcatheter aortic valve replacement on right ventricular-pulmonary artery coupling. JACC Cardiovasc Intervent. 2019:12:2145-54

27. Stachon P, Kaier K, Zirlik A, Bothe W, Heidt T, Zehender M, Bode C, von Zur Muhlen C. Risk-adjusted comparison of in-hospital outcomes of transcatheter and surgical aortic valve replacement. J Am Heart Assoc. 2019;8:e011504.

28. Spitzer E, Van Mieghem NM, Pibarot P, Hahn RT, Kodali S, Maurer MS, NazifTM, Rodes-Cabau J, Paradis JM, Kappetein AP, Ben-Yehuda O, van Es GA, Kallel F, Anderson WN, Tijssen J, Leon MB. Rationale and design of the transcatheter aortic valve replacement to unload the left ventricle in patients with advanced heart failure (TAVR UNLOAD) trial. Am Heart J. 2016;182:80-8.

\section{Publisher's note}

Springer Nature remains neutral with regard to jurisdictional claims in published maps and institutional affiliations.

Ready to submit your research? Choose BMC and benefit from:

- fast, convenient online submission

- thorough peer review by experienced researchers in your field

- rapid publication on acceptance

- support for research data, including large and complex data types

- gold Open Access which fosters wider collaboration and increased citations

- maximum visibility for your research: over $100 \mathrm{M}$ website views per year

At BMC, research is always in progress.

Learn more biomedcentral.com/submissions 